\title{
一流本科专业建设背景下突出应用特色的多元化实践课程 体系建设
}

田宽 ${ }^{1}$, 谢冰 ${ }^{1}$, 孙雨安 ${ }^{1,}{ }^{*}$, 赵建波 ${ }^{1}$, 刘军伟 ${ }^{1}$, 屈凌波 ${ }^{2}$

1 郑州轻工业大学材料与化学工程学院, 郑州 450001

2 郑州大学化学学院, 郑州 450001

摘要: 在新时期教育部推动一流本科专业建设项目的背景下, 作为一所地方性应用型高校, 郑州轻工业大学应用化 学专业在国家一流专业建设过程中, 依托综合实验课程、国家级实践教学基地、产学研合作以及大学生学科竞赛等 单元, 建设起独具应用特色的多元化创新创业实践平台和人才培养体系, 为一流专业建设中强化学科分层次发展和 重点建设, 提升应用化学专业人才教育质量提供了一种可供借鉴的模式。

关键词: 一流专业; 应用化学专业; 实践教学

中图分类号: G64; O6

\section{Exploration on the National First-Class Major Construction of Multi- Practical Courses with Prominent Application Characteristics}

\author{
Kuan Tian ${ }^{1}$, Bing Xie ${ }^{1}$, Yu'an Sun ${ }^{1,}{ }^{*}$, Jianbo Zhao ${ }^{1}$, Junwei Liu ${ }^{1}$, Lingbo Qu ${ }^{2}$ \\ ${ }^{1}$ Department of Material and Chemical Engineering, Zhengzhou University of Light Industry, Zhengzhou 450001, China. \\ ${ }^{2}$ College of Chemistry, Zhengzhou University, Zhengzhou 450001, China.
}

\begin{abstract}
Faced with the first-class major construction of higher education in the new era, Zhengzhou University of Light Industry, which is a local application-oriented university, relies on comprehensive experimental courses, national practice teaching base, industry-university-research cooperation, college students' discipline competition and other units in the process of national first-class applied chemistry major construction. The construction of a unique diversified innovation and entrepreneurship practice platform and talent training system provides a reference model for strengthening the development of disciplinary hierarchy and key construction in the first-class specialty construction, and improving the education quality of applied chemistry major.
\end{abstract}

Key Words: First-class major; Applied chemistry major; Practical education

2019年4月2日，国家教育部办公厅颁发了《关于实施一流本科专业建设 “双万计划” 的通知》， 正式开启了全国范围内一流本科专业建设的步伐。一流本科专业是办好一流教育、培养一流人才的 基础, 只有把人才培养方案、课程、教材、教师、实践教学平台和教学方法等都在一流专业这个平 台整合好, 把专业建设办扎实, 并办出特色、办出高水平, 才能真正培养出一流的人才, 从而实现 高等教育内涵式发展的目的。工程实践能力和创新能力的培养是应用型人才培养的主要目标之一。

收稿: 2021-07-25; 录用: 2021-07-28; 网络发表: 2021-09-02

“通讯作者, Email: sya@zzuli.edu.cn

基金资助: 郑州轻工业大学博士启动基金(13501050073); 中西部地方高校一流化学本科专业建设研究与实践(H20210609); 2020年产学合作协同 育人项目：应用化学进阶实验虚拟仿真系统开发(202002060025) 
实践教学是工科专业人才培养的重要途径 ${ }^{[1]}$ 。传统的实践教育体系主要是以课程实验、课程设计、 实习和毕业设计等主要环节为主。随着科技发展和产业变革, 特别是在 “新工科” 背景下, 如何加 强学生实践能力和创新意识成为了专业教学改革中的重要课题。现行的工程教育专业认证从运用工 程知识、设计和开放解决问题的办法、现代工具的使用以及项目和工程管理这四个维度, 对高校实 践教学改革指引了方向 ${ }^{[2,3]}$ 。国内众多高校对人才培养在 “新工科” 背景下的实现途径、方法和过程 进行了研究, 取得了很多有益的成果。郑州轻工业大学国家一流专业一一应用化学专业, 结合自身 专业特点以及应用型人才培养目标, 建立起一套多元化的实践教学体系, 对一流专业建设和提高 “新 工科”背景下的应用型人才的培养质量具有重要的实践意义。

\section{1 本专业实践教学体系建设的指导理念与发展现状}

郑州轻工业大学应用化学专业是由我校原工业分析专业发展而来的, 是一个以工为主, 理工 渗透, 化学、化工、材料、环保等多学科交叉的复合型专业。实践教学一直是本专业建设过程的重 点 ${ }^{[4]}$ 。本专业率先在本校建立起分析化学虚拟仿真实验平台, 开设进阶实验课程, 并鼓励学生积极 参与专业教师的科研项目, 通过深入科研项目的过程, 培养学生的创新思维。通过以上方式, 初步 建立起了以本校应用化学系的系训 “手脑并用” 为理念的系统而科学的实践教学体系。

围绕国家创新驱动发展等重大战略需求, 教育部提出了 “新工科” 人才培养理念, 在 “新工科” 背景下, 本专业依托以往建立起的实践教学平台, 为满足未来新工业需要的应用型、技能型和创新 型高素质人才的目标, 进一步强化校企联合培养, 打造了国家级实习实训基地, 建立了一套灵活的 校企联合培养模式。此外, 本专业为拓展学生的国际视野, 积极组织学生参加国内外专业会议。并 通过鼓励学生参加各类专业竞赛活动, 提升学生的动手能力和专业技能。并进一步拓展实践平台, 鼓励学生依据个人兴趣, 跨专业、跨院系参与科研项目。在 “新工科” 教育理念的指导下, 改革实 践教学理念, 完善和丰富实践教学内容, 建设起以校企联合培养和跨学科培养为基础的, 重实践、 强理论的实践教学体系。

2020年, 应用化学专业被评为河南省一流专业和国家一流专业, 本专业在教育部 “双万计划” 做强一流本科, 建设一流专业, 培养一流人才的目标指引下, 把实践教学作为本专业一流专业建设 和培养应用型一流本科人才的特色之一, 依据我校创新创业学分和原有实践教学体系, 通过细化创 新创业学分制, 加入兴趣小组和导生制培养模式等新思路, 建立起以学生兴趣为引导, 学生主动参 与的, 多领域的多元化创新创业实践课程体系。并以该特色的多元实践教学体系来达到强化应用型 人才培养, 以及建设具有地方特色, 满足区域需求的应用型一流本科专业的目标。

\section{2 多元化实践教学体系建设现状}

\section{1 校企联合培养}

实践教学是应用型人才培养的重要环节。以往化工专业的实践课程主要以实验课为主, 新工科 要求人才培养要面向具体工程问题的解决, 而一流专业则要求人才培养过程中要积极结合区域需求, 这都要求地方应用型高校要积极与相关企业合作, 通过校企联合的方式提升学生解决实际问题的能 力 $^{[5]}$ 。本专业一直都极为重视校企结合的实践教学模式, 根据自身专业特色和优势, 先后与河南省 畜牧局、河南省农科院、郑州海关、平顶山神马尼龙化工有限责任公司等省内企事业单位积极合作, 建立实习基地和灵活的校企联合人才培养模式。通过积极合作, 本专业在校企联合培养实践教学方 面取得了较好的成功。不仅建立了大量实习基地, 还利用暑期实习和毕业设计等方式, 让学生到企 事业单位中进行长期实习实践, 培养学生分析和解决实际问题的能力。本专业的校企联合培养模式 不仅收获了国家级项目, 如 “郑州轻工业学院-河南神马尼龙化工有限责任公司工程实践教育中心” 不仅获评为教育部地方所属高校 “本科教学工程” 大学生校外实践教育基地建设项目, 还受到省内 相关单位的认可, 如本专业学生受邀作为 “河南省第五届畜产品质量安全检测技能竞赛” 裁判。这 
些都是本专业长期坚持校企联合培养的成果。

\section{2 跨学科多领域}

应用化学专业是一个典型的多学科交叉的复合型专业, 我校应用化学专业的定位是以培养在化 工、环保、医药、食品安全、品质管理、无机非金属材料等相关领域从事科学研究、技术开发和管 理的应用型人才为目标。为了满足复合型应用人才的培养目标, 提升学生的创新思维与能力, 本专 业一直积极依托专业教师的科研项目, 鼓励和引导本科生参与其中。通过在科研项目中的学习, 培 养学生的创新思维和创新能力。在此基础上, 为进一步建设好国家一流专业, 满足社会对复合型创 新人才的需求, 本专业开始与其他专业的教师建立联合培养平台, 依据学生的兴趣, 引导学生跨学 科加入其他专业教师的科研项目, 让学生可以不局限于本专业知识的学习, 依据兴趣更多地了解跨 专业、跨学科的知识, 以及学会如何将本专业知识应用于其他专业, 如环境工程、食品安全、烟草 工程、精细化工等, 从而达到多学科交叉联合培养学生创新思维的目的。通过积极引导学生参加科 研项目, 本专业近三年来, 学生发表论文和专利数量明显上升, 每年申报 “互联网+” 等创新型比赛 的申报项目数量也明显提升。通过建立跨学科培养模式, 不仅引导学生更好地发展自己的兴趣, 也 很好地达到了培养学生创新意识的目的。

\section{3 以兴趣为引导}

兴趣是最好的导师。心理学研究表明, 没有愉悦的心情、高昂的兴趣, 学习就是沉重的负担 ${ }^{[6]}$ 。 通过兴趣引导可以发挥学生自主学习的能动性, 利用这种高涨的情绪和能动性, 可以更好地达到人 才培养的目标。本专业依据这一教学心理学现象, 创新性地以兴趣小组为单位, 开展实践教学活动。 组建了尽享技能兴趣小组、化工大赛兴趣小组、计算机兴趣小组、多媒体兴趣小组等。依托学生兴 趣, 让学生可以通过兴趣小组活动尽快了解大赛的内容和相关技能, 为各类全国大学生技能竞赛储 备选手。此外, 计算机和互联网多媒体作为新兴的工具, 受到社会各方面的关注。大量学生对计算 机网络技术有浓厚的兴趣, 本专业依托原有的虚拟仿真实验平台, 建立计算机兴趣小组, 让学生利 用计算机这一工具, 结合本专业实验课程, 自己动手建立新的虚拟仿真实验课程。通过这种结合兴 趣和专业知识的实践活动, 不仅锻炼了学生利用计算机技术的能力, 还有利于完善本专业的虚拟仿 真实验教学内容, 该兴趣小组的学生还利用这一项目, 申请了两项 “互联网+” 项目。本专业建立的 这种以学生兴趣为导向的兴趣小组实践活动受到了学生的欢迎, 也为加强跨学科综合型人才的培养 目标打下了基础。

\section{4 导生制模式}

大学生学科竞赛是面向大学生的专业素质类的竞技活动, 受到了社会和高校的普遍关注。它是 整合课堂和课外实践教学的重要组成部分, 相比于普通课堂教学和实验课程, 在创新教育改革、优 化人才培养和提高教学质量等方面有着独特的、不可替代的功能 ${ }^{[7]}$ 。本专业一直都极为重视组织学 生参加学科竞赛和创新创业大赛, 且在各类国家级大学生竞赛中取得了优异的成绩。但随着学生 对竞赛的兴趣和参与度的提升, 单纯地依靠传统导师指导的模式很难满足大量学生的需要。为了适 应学生的需求, 为学生提供更好的实践平台, 本专业不仅建立了兴趣小组的实践教学模式, 还积极 组织校级比赛, 引导学生积极参与。在此基础上, 本专业开创性地建立起一套以获奖学生参与竞赛 组织和培训的 “导生制” 实践教学模式。这种由学生指导学生的方式, 不仅使获奖学生的经验通过 自由开放的交流得以传承, 还解决了参赛学生多而指导教师少的被动教学问题。导生制模式的引 入, 不仅满足了兴趣小组对场地和时间的不确定性的需求, 还为学生提供了锻炼自身的平台, 让获 奖学生完成从 “学会” 到 “会学” 的转变, 使其对所学实践技能有了更深层次的理解。此外, 这种 模式还增强了学生的交流能力和表达水平。通过导生制的引入, 本专业近三年在国家级竞赛中获得 一等奖3项、二等奖9项、三等奖2项的好成绩。为本专业一流专业建设打下了坚实的基础。

\section{5 强化综合能力}

高等教育过程中, 实验课程是十分重要的实践教学环节。本专业在人才培养过程中设置了大量 
的实验, 如分析化学实验、仪器分析实验、材料科学基础实验、合成化学实验等。这些课程实验可 以很好地补充课堂教学。为进一步强化学生的专业实践技能, 本专业专门设置了与基础实验相对应 的能力进阶实验。在学生掌握基础实验技能后, 进一步提升实验要求, 以达到强化学生基础实验能 力以及实践动手能力的目的。在此基础上, 在第 6 和第 7 学期增设综合性实验, 将材料设计与合成、 分离与提纯、表征与分析以及器件制备与性能测试综合设计成实验课, 使学生通过该实验, 将分散 的专业知识进行综合应用, 提升学生的综合实践能力, 为本科毕业设计打基础。除了进一步加强实 验课程外, 本专业还十分注意扩展学生的视野。经常邀请国内外专家为学生作专题报告, 并积极组 织学生参加大型国际会议, 增强学生对本专业理论知识在实际应用中的发展现状和未来前景, 并让 学生对专业知识的综合应用产生直观的理解, 进而提升学生的综合实验能力。

\section{3 多元化实践教学体系的可持续发展}

为建设好应用化学 “一流专业”, 满足 “新工科” 背景下应用型人才的培养需求, 本专业还将 持续完善和改进现有的多元化实践教学体系, 并进一步完善实践教学效果的评价与认证体系。目前, 本专业主要以专业人才培养计划中 “创新创业课程” 为主体, 通过细化创新创业学分的认定细则, 来达到对学生实践教学效果的评价与认定。分别会在第 4 学期进行一次中期检查, 在第 8 学期进行最 终认定。通过中期检查, 提醒创新创业学分不足的学生要抓紧参与实践教学活动。第 8 学期第一周会 要求学生自行汇总创新创业学分的获得情况, 并提供相关资料与证书。为学生进行第一次评定, 对 不合格的认定要求进一步改进。第15周要求学生提交最终创新创业课程的相关材料, 为学生评定成 绩。通过中期检查, 可以更好地督促学生参与实践教学活动, 也可以帮助专业教师和辅导员发现未 参与实践教学的学生, 从而让指导教师更好地引导学生进行实践活动, 更好地提升了实践教学在人 才培养中的效果。

除了完善实践教学体系中的监督和引导环节外, 一定时间后, 本专业会根据人才培养需求对创 新创业学分的评定和认证细则进行修改。如在大学生竞赛刚兴起时, 学生参与度较低, 为了引导学 生积极参与各类大学生学科竞赛, 创新创业学分评定细则中将 “参与校赛” 评定为 1 学分。在学生参 与竞赛积极度提高后, 参赛学生人数增大, 本专业将 “参与校赛” 的评定分数降级, 从而更好地鼓 励学生努力训练, 争取参与省级和国家级比赛。依据人才培养需求及时修订评定细则, 更好地起到 了引导学生参与实践教学活动的积极性和主观能动性的作用。

\section{4 结语}

教育部实施 “双万计划”, 是新时代高等教育内涵式发展政策的深化, 是政府层面以建设一流 本科专业为指向的具体政策行为。郑州轻工业大学作为一所地方应用型大学, 在一流专业建设背景 下, 紧抓机遇, 积极支持各专业申报和建设国家一流本科专业。本校应用化学专业在结合地方经济 发展需求和进行特色化发展方面的着力聚焦, 通过校企联合、校内多学科协同、综合创新实验课程 建设以及积极组织学科竞赛等方式, 建立起专业实践教学平台。并在实践教学改革过程中, 聚焦学 生兴趣引导, 细化和完善评价标准, 并配以特色的 “导生制” 模式, 打造了独具专业特色的多元化 实践教学体系。以这种特色实践教学体系作为专业特色, 打造应用化学国家一流本科专业, 并促进 了本校本科建设水平更上一层楼。

\section{参 考 文 献}

[1] 何剑飞, 章国平. 高等职业教育探索, 2019, No. 5, 8 .

[2] 阮仪, 吴佳忆, 曾染龙. 高教学刊, 2019, No. 18, 141. 


\author{
[3] 王蕾, 葛军. 江苏高教, 2021, No. 5, 68 . \\ [4] 王淑坤, 王金龙, 李学光. 大学教育, 2019, No. 10, 20. \\ [5] 张立明, 陈福山, 孙德四. 甘肃联合大学学报(自然科学版), 2009, 23 (2), 126. \\ [6] 赵洁婷, 包文斌, 吴迪. 科技创新导报, 2017, 14 (35), 219. \\ [7] 钟劲茅, 邓安民, 王承宜, 舒红英, 周韦. 大学化学, 2006, 21 (4), 28.
}

\title{
欢迎订阅《物理化学学报》
}

2022 年全国报刊杂志征订工作已经开始, 敬请向贵单位推荐订阅 2022 年《物理化学学报》。

《物理化学学报》是由中国科学技术协会主管, 中国化学会和北京大学共同主办, 北京大学化学与分子 工程学院学报编辑部编辑出版的学术刊物。设有 “亮点”、“当期推荐”、“通讯”、“展望”、“专论”、 “综述”、“论文”、“人物专访” 等栏目, 报导物理化学学科及交叉学科的基础研究及应用研究的创新成 果。

中国科学院院士唐有祺先生担任名誉主编, 中国科学院院士、北京大学刘忠范教授担任主编; 编委会中 有 10 位两院院士, 1 位加拿大科学院院士, 2 位海外学者。 2004 年, 获得国内期刊界最高奖一一第三届国 家期刊奖百种重点期刊奖； 2015 年入选国家新闻出版广电总局 “百强报刊” 。中国科协精品科技期刊工程 项目资助出版。读者普遍认为《物理化学学报》具有极高的学术价值和收藏价值。WoS 公布的 2020 年影响 因子为 2.268 。

《物理化学学报》已被美国《科学引文索引》 $(\mathrm{SCI})$ 网络版、美国《化学文摘》 $(\mathrm{CA})$ 、日本《科技文献速 报》、俄罗斯《文献杂志》(AJ)、中国科协和国家自然基金委主办的《中国学术期刊文摘》、中国科学技术 部万方数据网络中心的《中国科技论文与引文数据库》(CSTPCD)、中国科学院文献情报中心的《中国科学 引文数据库》、中国生物学文献数据中心的《中国生物文摘》等国内外多种著名检索刊物和文献数据库摘引 和收录。

《物理化学学报》现为月刊, 大 16 开本, 亚光铜版纸印刷。 2022 年订价 50.00 元/册, 全年订价 600.00 元。国内邮发代号 82-163, 欢迎国内读者到当地邮局订阅, 国外读者可通过中国国际图书贸易总公司订阅 (Code No 1443-MO)。若通过邮局订阅有困难或错过订阅, 请直接与编辑部联系。欢迎广大科技工作者、科 研单位、高等院校、图书馆订阅。

地址: 北京大学化学学院《物理化学学报》编辑部

邮编: 100871

电话: +86-10-62751724

邮箱: whxb@pku.edu.cn

网址: http://www.whxb.pku.edu.cn 